\title{
O PACIENTE CIRÚRGICO - RELAÇÃO MÉDICO PACIENTE
}

\author{
THE SURGERY PATIENT - MEDICAL DOCTOR-PATIENT RELATIONSHIP
}

Reginaldo Ceneviva, Orlando de Castro e Silva Jr

Docentes da Divisão de Gastroenterologia Cirúrgica do Departamento de Cirurgia e Anatomia da Faculdade de Medicina de Ribeirão Preto - USP

CorResPondÊncia: Reginaldo Ceneviva. Divisão de Gastroenterologia Cirúrgica do Departamento de Cirurgia e Anatomia da Faculdade de Medicina de Ribeirão Preto - USP. Av. Bandeirantes, 3900. CEP: 1408-900 - Ribeirão Preto / SP.

Ceneviva R, Castro e Silva Jr O. O paciente cirúrgico - relação médico paciente. Medicina (Ribeirão Preto) 2008; 41 (3): 252-8.

RESUMO: O bom exercício da medicina exige preparo cognitivo, técnico, afetivo e ético do médico. O cirurgião, além do conhecimento das doenças e de habilidade na técnica cirúrgica, deve entender que o paciente está inserido em um contexto psico-social amplo e que o sucesso da terapêutica está baseado na boa relação médico-paciente, relacinada a todos esses fatores.

Palavras-chave : Relações Médico-Paciente. Cirurgia. Ética.

\section{1- INTRODUÇÃO}

A boa assistência médica prevê o atendimento do paciente como um todo, com atenção que privilegia o doente em relação à doença.

Toda doença orgânica carrega consigo um componente psíquico que, não raramente, é mais importante que ela, pelo que é possível caracterizar o atendimento psicológico associado como um procedimento essencial à recuperação da saúde. No atendimento global avalia se ainda como o paciente está inserido no seu contexto psicossocial e familiar, o que justifica, em parcela significante de casos, o concurso de equipe multidisciplinar que inclui psicólogo e assistente social.

O sucesso da terapêutica baseia se, entre outros fatores, na boa relação médico paciente em que são fundamentais a atenção aos problemas orgânicos e psíquicos e o respeito aos princípios éticos e legais.

\section{2- FORMAÇÃO DO MÉDICO}

Qualquer que seja o modelo curricular das escolas médicas, a formação de um "bom médico" assenta se em três elementos básicos indissociáveis: conhecimentos, habilidades e atitudes. O conhecimento organiza se a partir das informações provindas de instrutores e, principalmente, de muito estudo; a habilidade resulta de treinamento continuado e do aprendizado conferido pelas experiências vividas na prática dos atos médicos; a atitude médica protótipo de sua formação psicológica depende, entre outros fatores, do temperamento, moral, personalidade, ética, caráter, atributos do ego, identidade e, em última análise, é a co-responsável pela qualidade da relação médico paciente ${ }^{1}$.

No seu preparo, além do conhecimento sobre fisiologia, bioquímica, patologia, clínica, radiologia e metabologia, indispensáveis para o diagnóstico e 
condução dos cuidados pré e pós operatórios, o cirurgião necessita de conhecimentos adicionais técnicos e anatômicos para bem conduzir o ato operatório, aliados à correta observação dos aspectos psicológicos e éticos da relação médico-paciente.

\section{3- ASPECTOS PSICOLÓGICOS}

\section{1- A Doença}

A doença orgânica implica sobrecarga emocional decorrente das características próprias do psiquismo de cada paciente e de uma série de perigos e prejuízos reais que incluem risco de vida, mutilação anatômica e/ou funcional, prejuízos econômicos por inatividade e despesas extras, postergação de planos e mesmo expectativa quanto à capacidade médica e hospitalar. $^{2}$

\section{2- O Paciente}

A instalação da doença orgânica, sobretudo se associada à necessidade de hospitalização, modifica significativamente a vida do paciente. Inatividade, perda do controle pessoal, dúvidas quanto ao restabelecimento e à cura e temor da morte geram tensão emocional que dificulta a compreensão dos fatos.

No hospital fica à mercê de condutas adotadas pela equipe que o atende e a normas que envolvem a rotina hospitalar relativas a horários, exames, visitas, mudanças nos hábitos, na roupa e na alimentação, inibindo suas iniciativas e passando a depender mais explicitamente dos outros. Isto é mais grave nos hospitais escola, onde o doente não tem o "seu" médico e é atendido por uma série de rostos não familiares, onde são perdidos seu espaço e sua privacidade, e o sentimento de perda e solidão pode levá lo a um processo de depressão situacional ${ }^{3}$.

A doença costuma levar o doente a um estado de regressão, com fantasias e expectativas próprias da época em que era criança.

A tensão emocional é tanto maior quanto maiores forem as incertezas e o grau de desinformação, que favorecem a elaboração de idéias fantasiosas.

São muitos os fatores que podem desencadear a regressão, mas o distúrbio emocional que surge é sempre fruto das características psicológicas próprias de cada paciente. Os significados simbólicos de ordem psíquica que acompanham a doença orgânica correlacionam se com modificações na imagem corporal, o que, além do sofrimento físico e a falta de compreensão dos fatos, pode gerar fantasias e sentimentos não raramente contraditórios de temor, respeito, ciúme, obediência, burla, desamparo, confusão, culpa, exigência de garantia de sucesso ${ }^{1,2}$.

O médico é geralmente visto pelo paciente, na situação de regressão, como uma figura paternal poderosa e onipotente, fenômeno conhecido como transferência que, em função de sentimentos contraditórios, pode ser positiva ou negativa, variando de extrema dependência até a hostilidade.

O paciente necessita de cuidados e amparo, sobretudo pela exacerbação desses problemas na vigência da necessidade de uma intervenção cirúrgica.

As emoções do paciente a ser operado são muito diversas, desde a satisfação de um desejo inconsciente de castigo ou de uma forma de escapar de algo que ele teme mais que a cirurgia até a expectativa, exagerada para certas situações, de que o cirurgião elimine o mal e, conseqüentemente, traga a cura, sem qualquer desconforto e sem complicações. A cobrança pelos familiares da garantia de êxito total aumenta o conflito emocional e a responsabilidade médica.

\section{3- O Cirurgião}

De maneira geral, toda a responsabilidade é depositada no cirurgião que, sob certos aspectos, é visto como o senhor da vida e da morte. Nessa situação, o cirurgião pode ser influenciado negativamente por esse clima, sentindo ansiedade, tensão, insegurança. ${ }^{2}$

O sentimento do médico em relação a seu paciente é conhecido como contratransferência e decorre de sua resposta às angústias nele depositadas pelo paciente ${ }^{1}$.

A postura inadequada do médico, desde a aceitação inconsciente de onipotência até a conduta apática e de resignação, traduz o seu despreparo e o caráter emocional dessas situações, e pode trazer sérias conseqüências quanto ao sucesso do tratamento e ao conforto do paciente, incluindo o abandono de pacientes terminais.

Sentimentos negativos como culpa, depressão, irritação, além da onipotência, por parte do cirurgião, podem fazer com que ele inconscientemente evite confronto com as próprias e naturais limitações e com as frustrações na tentativa de se conseguir a cura do paciente, e tome atitudes extremadas, que incluem 
desde medidas heróicas e desnecessárias de grandes intervenções, até o abandono de pacientes que poderiam usufruir de sua atuação com menor desconforto e sobrevida de melhor qualidade.

A capacidade de aceitação de sua própria limitação em face de situações mais críticas que impedem a cura traduz maturidade emocional do cirurgião. A imaturidade frequientemente resulta no distanciamento emocional e refúgio na técnica.

A cirurgia é uma agressão orgânica e psíquica e não deve ser simplificada a um ato técnico.

A inter relação adequada depende da estrutura psíquica do médico e do paciente e da postura do médico que, em um processo de colaboração mútua, deve saber escutar e esclarecer seus pacientes.

A firmeza e a correção das atitudes iniciais são indispensáveis na minimização de problemas futuros. Uma das deformações mais comuns é a que procura ver o cirurgião como um ser onipotente, capaz de evitar o sofrimento e a própria morte. Ceder à tentação de permitir o crescimento exagerado de sua própria imagem constitui um erro grave, comum em profissionais despreparados técnica, afetiva e moralmente para o exercício da medicina. Por outro lado, a transparência de indecisão e dúvida somente é tolerada em doses muito pequenas, sob pena de afetar grandemente a segurança do paciente. ${ }^{4}$

O médico, no caso especial, o cirurgião, exerce grande influência sobre seus pacientes, e suas atitudes podem favorecer o bem estar e a cura ou, ao contrário, a piora e disfunção.

A concepção muito impregnada no senso popular e entre os profissionais da saúde de que a doença orgânica possui um status maior em relação aos problemas psíquicos favorece a subvalorização dos aspectos emocionais dos pacientes.

A transferência e a contratransferência são simultâneas e interativas e configuram em cada situação médica um vínculo muito singular que, se adequado, tem na maioria das vezes um curso natural e produtivo.

A influência do cirurgião sobre o paciente depende muito mais da qualidade do que da quantidade de atenção dispensada, fruto natural da personalidade e traços de caráter do cirurgião. O cirurgião deve assumir uma posição firme e neutra, na medida adequada às necessidades do paciente.

A existência e o grau de ansiedade e insegurança do paciente devem ser atentamente observa- dos. A criação de um clima que permita ao paciente, dentro de seu próprio ritmo, ir expondo ou deixando perceber seus temores, abre espaço para que sejam esclarecidos seus problemas e as propostas médicas, na justa medida de sua capacidade e disposição de conhecê los. Ao observador atento, ficam claros em alguns pacientes os limites para o exercício da verdade. A ultrapassagem desses limites somente deve ocorrer por razões bastante consistentes ${ }^{4}$.

O binômio médico paciente vem gradativamente modificando se para o modelo de forças dinâmicas em que se entrecruzam necessidades, desejos, expectativas, valores, sentimentos, angústias, pressões, etc. Essas forças não se processam somente na direção do médico para com a doença e o doente, mas também com os familiares deste, com o hospital e todo o seu pessoal, com a instituição que paga, com a sociedade que lhe cobra, e, principalmente, na relação consigo mesmo. A tendência é a de uma maior participação do doente e da família enquanto a figura deificada do médico vai decrescendo a níveis em que ele se imporá pela sua real competência. O paciente deixa progressivamente de seguir cegamente a conduta que lhe é traçada e cada vez mais quer ser esclarecido e participativo nas decisões ${ }^{1}$; dessa maneira, vai desaparecendo a relação médico paciente do tipo autoritarismo passividade em favor de relações mais saudáveis e produtivas.

O tipo de personalidade do médico é, sem dúvida, um importante fator determinante da qualidade da relação médico paciente; a formação de um bom médico não exige, porém, um determinado tipo padronizado ${ }^{1}$.

A boa relação médico paciente relaciona se com alguns atributos do médico, entre outros:

- Esquema referencial que consiste no conjunto de conhecimentos, afetos e experiências com os quais o médico pensa, age e se comunica.

- Ação psicoterápica, manifesta ou latente.

- Capacidade de fazer a integração biopsicossocial.

- Capacidade de intuição e empatia.

- Capacidade de ser continente, isto é, poder conter as angústias, fantasias e necessidades de seu paciente aflito e suas próprias angústias e dúvidas.

- Capacidade de comunicação, que não se restringe à forma verbal. Para uma boa relação com o paciente, o médico necessita saber escutar, isentar se de preconceitos, não tentar catequizar seus pacien- 
tes com julgamentos morais e padrões de comportamento, evitar a perda da delimitação dos papéis na contratransferência, evitar o descompasso semântico e saber lidar com as verdades. O descompasso semântico consiste no uso de palavras ou jargões técnicos que para o médico tem um significado e para o paciente tem outro, às vezes, o oposto. Ao lidar com as verdades, o médico deve ser capaz de ouvir, reconhecer e comunicar as verdades penosas $^{1}$.

É importante comunicar se mediante linguagem de compreensão clara, sem nunca fugir da verdade, respeitando-se ritmo e dosagem ditados pelo paciente, sem ferir a sua auto-estima e, principalmente, nunca desesperançá lo totalmente ${ }^{1}$.

No período pré operatório, além da anamnese pormenorizada, exame físico cuidadoso e exames complementares para avaliação do estado nutricional, das funções cárdio-respiratória e renal, da hemostasia, do estado de hidratação, o cirurgião deve conhecer as condições psicodinâmicas e sociais do paciente.

A reação emocional do paciente no pré operatório é variada, de maneira geral sua ansiedade é proporcional à gravidade da situação clínica e ao grau de desinformação. A tranqüilidade que apresenta freqüentemente é apenas aparente; existem geralmente ansiedade e insegurança decorrentes da expectativa de dor, sofrimento, morte e mutilação. A anestesia gera temor, quase sempre maior do que a própria intervenção cirúrgica e, do ponto de vista psíquico, pode assemelhar se à morte pelas implicações de abandono e passividade.

O paciente deve ser informado sobre a seqüência do evento do pré e do pós operatório, com o grau de detalhamento compatível com o seu psiquismo e situação clínica. Não se devem criar expectativas exageradas com relação aos resultados do tratamento cirúrgico, o que depois pode gerar decepção e desconfiança do paciente ${ }^{1}$.

O cirurgião deve fazer uma abordagem direta, simples e objetiva quanto aos riscos, dor, desconforto, exames, enfim, informações mais próximas da realidade; meias verdades são permitidas quando elas representam um respeito à integridade psíquica e à dosagem ditada pelo próprio paciente.

A regressão é fenômeno que se inicia no período pré-operatório e se exacerba no pós operatório imediato.
A agressão orgânica e psíquica, correspondente à doença orgânica, hospitalização, anestesia e cirurgia, resulta em reação neuroendócrina e metabólica, em princípio, proporcional ao grau de agressão e à capacidade de reação do organismo.

No pós operatório imediato o paciente apresenta dor e alterações fisiológicas, voltando se principalmente para o próprio corpo, desinteressado do contato com o meio que o cerca; este período recorda fases muito precoces da vida infantil em que a criança está voltada quase exclusivamente para suas próprias sensações; a dependência com o cirurgião exacerba se.

À medida que a dor diminui e as alterações hormonais e metabólicas retornam ao normal, o interesse pelo mundo externo aumenta, paralelamente à disposição psicológica de curar se. A convalescença de certa forma é comparável ao período de crescimento, no qual gradativamente as características do comportamento adulto vão surgindo, ao passo que as posições infantis vão sendo abandonadas. Cabe ao cirurgião estimular uma conduta ativa, em princípio com deambulação e alimentação por via oral precoces, e a colaboração no próprio tratamento ${ }^{2}$.

É importante saber captar as várias formas pelas quais um paciente expressa sentimentos ocultos. Há pacientes, por exemplo, que não colaboram no próprio tratamento porque a recuperação implica a perda de vantagens e privilégios que lhe confere a condição de doente; alguns podem apresentar queixas sem correlação com a avaliação objetiva porque temem voltar à vida normal com seus naturais compromissos que não querem enfrentar, enquanto outros simulam estar bem visando à alta hospitalar.

Algumas situações são mais difíceis de ser abordadas rnantendo se o estabelecimento da adequada relação entre o médico e o paciente; incluem se entre elas o atendimento de emergência e os pacientes com câncer e/ou terminais.

A relação médico paciente no setor de pronto socorro dos hospitais públicos tem como característica o anonimato; médico e paciente encontram se pela primeira vez e quase sempre, de maneira recíproca, um não sabe o nome do outro. No momento da urgência, e temeroso pelo que se passa, o doente geralmente se depara com o desconhecido médico e hospital, sente se inferiorizado e, não raramente, reage com agressividade. Embora o tempo para o atendimento seja escasso, nada impede o médico de utilizá lo com educação e cortesia 5 . 
O setor de emergência, por outro lado, é estressante para a equipe de saúde. Pacientes alcoolizados, toxicômanos, homossexuais, idosos, histéricos, velhos e aidéticos podem não receber o mesmo grau de atenção que os politraumatizados e crianças, e nem os aspectos psíquicos recebem a devida valorização e cuidados.

Astúcia, rapidez de raciocínio e conhecimento científico são fundamentais no atendimento da emergência, mas não invalidam a preservação de uma boa relação humana ${ }^{5}$.

Não é fácil cuidar de doentes com afecções malignas ou doentes terminais, pois envolve uma reformulação constante e uma disponibilidade de trabalhar pessoalmente o aspecto vida morte; o sentimento de impotência de curar e salvar vidas é quase uma constante quando se está com um ser que está vivendo e morrendo ao mesmo tempo ${ }^{3}$.

A palavra câncer está impregnada da idéia de morte, e por isso mesmo o seu diagnóstico comunicado ao paciente vem com o estigma de condenação. A negação é a reação natural, o mecanismo de defesa geralmente empregado pelos portadores de doenças neoplásicas malignas; de maneira geral, os pacientes não querem saber a verdade. Com base nisso, especula se se seria melhor não informar o diagnóstico correto ao paciente visando reforçar seus mecanismos de defesa. Deve se questionar o uso do reforço à negação como adequado na maioria dos casos. Há uma tendência atual a relatar a verdade ao paciente canceroso como conduta preferencial e omitir o diagnóstico de neoplasia ao paciente como exceção.

Ao comunicar o diagnóstico, o médico deve fazê lo de forma clara, porém suave e respeitosa, evitando ser tanto evasivo quanto invasivo ${ }^{6}$.

Por ocasião do relato da verdade, o médico deve estar preparado e disposto a fornecer um respaldo psicoterápico no sentido de aliviar as ansiedades decorrentes dessa atitude 2 .

É importante enfatizar a falibilidade de qualquer atitude predeterminada, sem levar em conta as características individuais de cada caso.

O paciente tem o direito de saber sobre a sua doença e, salvo nos casos de crianças ou pacientes incapacitados de decidir, os familiares têm o mesmo direito se o paciente concordar em dividir algo de sua privacidade. Por outro lado, o médico tem o dever de informar ao paciente o seu diagnóstico e as possibili- dades terapêuticas com as seqüelas esperadas. Se o diagnóstico tiver sido comunicado de forma clara e enfática, o paciente mais facilmente adotará uma postura de compreensão e colaboração quanto ao tratamento, quase sempre muito agressivo ${ }^{6}$.

O paciente precisa ter um médico de referência que com ele deve se comprometer em todas as fases do tratamento. O trabalho integrado do médico com o psicoterapeuta resulta na melhor qualificação profissional de ambos e maior benefício para o paciente.

A cirurgia é, em princípio, a melhor terapêutica para a maioria das neoplasias malignas e, assim, é a grande esperança de cura para os pacientes. Pode se avaliar o efeito de uma cirurgia sob duas perspectivas: do ponto de vista do médico, isto é, do diagnóstico que ele faz da evolução e melhora do quadro orgânico consequientes à operação, e do ponto de vista do paciente, isto é, da maneira como ele interpreta o resultado da cirurgia e do significado que ela teve para sua vida pessoal. O grau de satisfação com a cirurgia depende da personalidade do paciente e da maneira corno ele aprendeu a enfrentar situações novas ou difíceis da vida cotidiana ${ }^{7}$. O paciente operado por câncer e os que o cercam devem se recondicionar em sua totalidade. Cabe ao psicólogo investigar a história de vida do paciente, o que ele pensa e sente, que hipóteses faz sobre sua doença e tratamento, quais são seus receios e suas expectativas, que mudanças percebe em si mesmo e no meio em que vive, e como lidar com sentimentos de angústia e perda. Esses dados ajudam a prever possíveis reações diante do diagnóstico e tratamento, como também a mobilizar os recursos disponíveis a fim de minimizar ansiedades ${ }^{6}$.

Para qualquer situação de assistência médica é importante o médico assumir atitudes adequadas para melhor beneficiar seus pacientes. Autoridade e passividade, como modalidade da relação médico paciente, têm sido abandonadas e substituídas por orientação e aceitação, com a tendência atual a se assumir a participação mútua como tipo de relação ideal.

\section{4- ASPECTOS ÉTICOS}

O paciente tem direito a atendimento humano, atencioso e respeitoso por parte, não somente do médico, mas de todos os profissionais de saúde e deve ser atendido em local digno e adequado. Por sua vez, a angústia do médico na elaboração do diagnóstico e, 
principalmente, na elaboração do prognóstico, é sentimento que não deve ser transferido ao paciente e nem aos seus familiares ${ }^{8-10}$.

O médico deve demonstrar segurança e confiança na sua orientação. As dúvidas podem ser discutidas com colegas que possam eventualmente contribuir para sua elucidação. Apenas depois de estabelecidos o diagnóstico ou medidas para sua elucidação, o paciente e seus familiares devem ser notificados.

O paciente tem direito a informações claras, simples e compreensivas, adaptadas à sua condição cultural, sobre as ações diagnósticas e terapêuticas, o que pode decorrer delas, a duração do tratamento e a sede de sua doença.

O paciente deve ter seus segredos resguardados, mediante manutenção do sigilo profissional, desde que não acarrete riscos a terceiros ou à saúde pública.

No Hospital Universitário, a relação médico paciente dilui se, transformando se em relação paciente equipe médica. Durante as tradicionais visitas médicas, instituídas nos hospitais europeus do século XIX, nas discussões que se estabelecem entre vários membros da equipe médica, revelam se abertamente o diagnóstico e/ou os supostos diagnósticos a todos aqueles que se encontram junto ao paciente. Óbvio que essa prática é importante para o ensino aprendizado, porém, deve se lembrar, sempre, que o fato de aprender não justifica o ato de expor o paciente a situações embaraçosas e antiéticas ${ }^{11}$.

Em 1991, o CREMESP posicionou se em relação à visita médica em hospitais escola, recomendando:
"Aos médicos, professores e estudantes que, durante suas preleções, aulas ou observações, se abstenham de comentários além dos exigidos para obtenção dos dados anamnéticos e semióticos indispensáveis, reservando se para em separado a discussão do caso, diagnóstico diferencial, hipótese diagnóstica, terapêutica e prognóstico, afim de evitar o constrangimento que tal prática possa acarretar".

Entretanto, apesar dos direitos invioláveis do paciente e do aspecto ético envolvido, ainda hoje, não raramente se vêem durante as visitas, e à frente do doente, médicos assistentes esbanjando saber técnico científico, muitas vezes, diante de chefes que se pontificam, sem contudo dar se conta da assumida postura antiética e desrespeitosa para com o paciente.

$\mathrm{O}$ aspecto ético na relação médico paciente, acima de valores ou conceitos morais, pressupõe respeito mútuo entre ambas as partes, para que o produto final seja o melhor possível, a manutenção da saúde e da vida.

O médico, como qualquer outro profissional, deve seguir preceitos éticos e legais. Não deve, sob pena de processos e punição, incorrer em desvios de conduta como imperícia, imprudência e negligência.

Para o bom exercício da medicina é fundamental o bom preparo cognitivo, técnico, afetivo e moral. No caso particular do ato cirúrgico, o cirurgião deve ser eclético, dominar as várias técnicas cirúrgicas e conhecer suas vantagens e desvantagens, para empregar a mais adequada para cada situação em particular e assim melhor beneficiar seus pacientes.

Ceneviva R, Castro e Silva Jr O. The surgery patient - medical doctor-patient relationship. Medicina (Ribeirão Preto) 2008; 41 (3): 252-8.

ABSTRACT: A good medical assistance requires a profound cognitive, technical, conscious, affective, and ethical preparation of the physician. Besides his knowledge about and the necessary know-how of surgical techniques, every surgeon should be aware of the patient's psychosocial situation, as well as of the fact that a relationship between the doctor and the patient, which involves all the above mentioned features, is crucial for the success of any therapy.

Key words: Physician-Patient Relations. Doctor-Patient Relationship. Surgery. Ethics. 


\section{BIBLIOGRAFIA RECOMENDADA}

1 - Zimerman DE. A formação psicológica do médico. In: Mello Filho J. Psicossomática hoje. Porto Alegre, Artes Médicas, p. 64-73, 1992

2 - Galvão OV, Groisman M, Azulay JD. Relação médico-paciente. In: Galvão L. Cirurgia do aparelho digestivo. Rio de Janeiro. Guanabara-Koogan, p. 282-9, 1978.

3 - Paiva LE, Pinotti HW. Câncer: algumas considerações sobre a doença, o doente e o adoecer psicológico. Acta Oncol Bras 8(3): 126-32, 1988.

4 - Barroso FL. O paciente e seu cirurgião. In: Mello Filho J. Psicossomática Hoje. Porto Alegre, Artes Mèdicas, p. 259-63, 1992,

5 - Alves JG. Aspectos psicossociais do atendimento de emergência. In: Mello Filho J. Psicossomática Hoje. Porto Aelgre, Artes Médicas, p. 244-9, 1992.
6 - Miceli AVP. Pré-operatório do paciente oncológico: uma revisão psicológica. Ver Bras Cancerol. 44 (2): 131-7, 1998.

7 - Giannotti A . Reflexões sobre a especificidade do trabalho de psicólogos na Saúde Pública, junto a pacientes com problemas orgânicos. Insight. Psicoterapia, 62: 31-4, 1996.

8 - Landmann J. Medicina não é saúde. 2a․ ed. Rio de Janeiro, Nova Fronteira, 1983.

9 - Pessini L, Barchifontaine CP. Problemas Atuais de Bioética. 4a. ed. São Paulo, Loyola, 1997.

10 - Segre M, Cohen C. Bioética. São Paulo, Edusp, 1995.

11 - Lima Filho MT. Visitas gerais à beira do leito: prática a ser mantida ou abandonada. Rev Paul Med, 106: 5, 1998.

Recebido para publicação em 20/08/2008

Aprovado para publicação em 30/09/2008 